\title{
REVISTA DE ENSINO EM ARTES, MODA E DESIGN
}

Dossiê 8

Práticas interacionais na construção

de práticas docentes: estudos do discurso

ISSN: $2594-4630$

\section{A MODA COMO DISPOSITIVO DA MEMÓRIA NO ESPAÇO MUSEOLÓGICO}

\author{
Fashion as a memory device in the museological space
}

La moda como dispositivo de memoria en el espacio museológico

Diêgo Jorge Lobato Ferreira ${ }^{1}$

Priscila Almeida Cunha Arantes ${ }^{2}$

\footnotetext{
${ }^{1}$ Mestre em Design pela Universidade Anhembi Morumbi (Bolsa Capes Prosup ) Professor do Instituto Federal do Maranhão - IFMA, Campus São Luís Centro Histórico com atuação na Licenciatura em Artes Visuais e na Pós-graduação Lato Sensu em Arte. Mídia e Educação do IFMA. Lattes: http://lattes.cnpq.br/3380086125867975 ORCID https://orcid.org/0000-0001-9547-3916 E-mail: diego.ferreira@ifma.edu.br

2 Pós-doutora em Arte Contemporânea pela Penn State University (EUA). Mestre e Doutora em Comunicação e Semiótica pela PUC SP. É professora do Mestrado e Doutorado em Design na Escola de Artes, Arquitetura, Design e Moda da Universidade Anhembi Morumbi. É diretora e curadora do Paço das Artes, Museu da Secretaria de Estado da Cultura de São Paulo deste 2007. Lattes: http://lattes.cnpq.br/9220155250600700 ORCID https://orcid.org/0000-0002-0500-0849 E-mail: priscila.a.c.arantes@gmail.com
} 


\title{
RESUMO
}

O presente artigo tem por objetivo estabelecer relações entre moda, memória e museu, tendo em vista a compreensão do fenômeno da moda que sai do lugar-comum e adentra os espaços museológicos. Assim, dedicamo-nos, também a examinar como a moda e o museu, enquanto campos de produção cultural, se estruturam, observando a produção e a obra do designer Hussein Chalayan. O referencial teórico compreende os seguintes autores: Le Goof (2013), Nora (1993), Crane (2008), Lipovetsky (2009), Sant'Anna (2010), Norogrando (2015), Andrade (2008). Este trabalho foi desenvolvido a partir do resultado de pesquisa exploratória adotando as seguintes etapas metodológicas: revisão de literatura, pesquisa documental e estudos de caso que pautaram as análises e sínteses apresentadas.

Palavras-chaves: Moda; Memória; Museu

\begin{abstract}
This article aims to establish relationships between fashion, memory and the museum, with a view to understanding the phenomenon of fashion that leaves the commonplace and enters the museum spaces. Thus, we are dedicated to examining how fashion and the museum, as fields of cultural production, are structured. The theoretical framework comprises the following authors: Le Goof (2013), Nora (1993), Crane (2008), Lipovetsky (2009), Sant'Anna (2010), Norogrando (2015), Andrade (2008). This work was developed from the result of exploratory research adopting the following methodological steps: literature review, documentary research and case studies that guided the analyzes and syntheses presented.
\end{abstract}

Keywords: Fashion; Memory; Museum

\section{Resumen}

Este artículo tiene como objetivo establecer relaciones entre la moda, la memoria y el museo, con el fin de comprender el fenómeno de la moda que sale de lo común y entra en los espacios del museo. Así, también nos dedicamos a examinar cómo se estructuran la moda y el museo, como campos de producción cultural, observando la producción y el trabajo del diseñador Hussein Chalayan. El marco teórico está compuesto por los siguientes autores: Le Goof (2013), Nora (1993), Crane (2008), Lipovetsky (2009), Sant'Anna (2010), Norogrando (2015), Andrade (2008). Este trabajo se desarrolló a partir del resultado de una investigación exploratoria adoptando los siguientes pasos metodológicos: revisión de la literatura, investigación documental y estudios de casos que guiaron los análisis y síntesis presentados.

Palabras-clave: Moda; Memoria; Museo 


\section{INTRODUÇÃO}

Ao observarmos o fenômeno da moda nos museus e sua associação com a memória, percebemos que essa relação se traduz na configuração de um jogo que se apresenta na forma dos objetos, que nos suscitam inúmeros debates acerca do modo de produção desses artefatos/roupa na nossa sociedade industrial.

Os estudos de Design de Moda e suas inter-relações no Brasil são recentes e, aos poucos, estão ganhando espaço na produção acadêmica brasileira. Diversos pesquisadores, de diferentes áreas de conhecimento, têm se dedicado às pesquisas que se relacionam com o fenômeno da moda. Neste contexto, este trabalho se apresenta como uma busca para compreender a relação entre moda, memória e museu, a fim de entender os deslocamentos da moda que adentram o espaço museológico.

A aproximação entre moda, museu e memória fornece o pano de fundo para o desenvolvimento desta pesquisa. De um modo geral, nossa proposta consiste em compreender a relação entre esses três elementos, observando a produção do designer de moda Hussein Chalayan em museus e galerias de arte. Para tanto, buscamos investigar a moda como um dispositivo de memória, pensando como se dá a sua entrada nos espaços museológicos. Além disso, examinamos as práticas e as representações a respeito da memória e de suas relações mais recorrentes, como: nomadismo, geopolítica, imigração, dentre outros.

A abordagem do tema desta pesquisa se situa a partir de uma perspectiva histórica e sociológica da moda, da prática do design e da memória, buscando investigar como a prática do designer de moda congrega os aspectos subjetivos e os valores sociais - simbólicos e econômicos - que embasam a moda.

Como corpus documental, apresentamos um panorama a respeito da moda no museu, destacando a questão da roupa como um indicador cultural de memória. A metodologia adotada é de caráter exploratório e qualitativo, compreendendo pesquisa bibliográfica, documental e estudos de caso que pautam as análises e sínteses realizadas. A organização do trabalho está estruturada nas seguintes partes: A moda no museu; A moda como dispositivo de memória; Estudo de Caso; Considerações finais; Referências. 


\title{
2 A MODA NO MUSEU
}

A moda tem adentrado os museus, a exemplo do Museu do Traje de Madri, Museo de la moda no Chile, Fashion Institute of Technology Museum nos Estados Unidos, Museu Nacional do Traje e da Moda de Portugal, dentre tantos outros dedicados exclusivamente ao tema. Diante disso, elencaremos alguns pontos importantes nesse processo da moda no museu e de seu possível surgimento nesse ambiente.

\begin{abstract}
Enquanto as últimas décadas do século $X X$ viam o aparecimento de museus da moda, que morre sempre jovem, os historiadores ainda se questionavam se não deveriam escrever sobre outra coisa que não a respeito desses fantasmas suntuosos e fugazes (ROCHE, 2007, p.19).
\end{abstract}

As exposições universais, que tiveram início no final do século XVIII, marcaram, sobretudo, o poderio industrial do século XIX, sendo precursoras das exposições nacionais da indústria, virando desta forma centros de "peregrinação" da mercadoria-fetiche, criando no grande público uma fantasia e um certo desejo de consumismo pelos objetos ali apresentados (FERREIRA, 2015).

Diante desse fenômeno histórico em que a concepção da moda passa a ser vista como objeto de estudo histórico, surgem, na segunda metade do século XIX, as primeiras instituições museais que mostram interesse pelos acervos de moda. $O$ Victoria and Albert Museum (V\&AM), uma das instituições museais mais importantes da Inglaterra, se originou partir da ideia de unir arte, design e indústria. Fundado em 1851, o museu consagrado às artes em geral tem um extenso acervo de pinturas, esculturas, gravuras objetos de metais, desenhos, mobiliário, fotografia e, ainda, roupas e acessórios, configurando-se como um dos grandes acervos em arte e design (FERREIRA, 2015).

Em 1900, é realizada a Exposição Universal em Paris, onde são expostos novas técnicas e recursos do ramo industrial, refletindo nas áreas de arte e moda. A primeira metade do século XIX é marcada por um período turbulento: a quebra da bolsa de valores de New York, em 1929, além das duas guerras mundiais. Em decorrência desses fatos, muitas maisons de Alta-costura entraram em crise, tendo em vista que o setor têxtil enfrentava fragilidades na Europa, onde a indústria estava voltada agora exclusivamente à produção bélica. 
Mesmo diante das guerras e conflitos, a moda adapta-se em meio à crise das guerras. $O$ vestuário fica mais austero, fazendo referência aos anos de guerra. $A$ moda apresenta traços, cores e modelagens que remetem aos uniformes militares.

Em 1925, a Exposição de Artes Decorativas de Paris abre as portas para que o estilo art-déco influencie várias áreas como a moda e a arte. Ainda no período entre guerras, surge o Museum of Costume Art, criado em 1937 por Aline Bernstein e Irene Lewisohn; em 1946, o espaço passou a integrar o Metropolitan Museum of Art. Em 1959, sob direção de Diana Vreeland, é criado o Costume Institute, um departamento especializado em exposições de moda. Entre suas principais exposições, encontram-se: The Word of Balenciaga (1973), Hollywood Design (1974), The Glory of Russian Costume (1976) e Vanity Fair (1977), colocando o museu no cenário internacional das exposições de moda (FERREIRA, 2015).

Durante a Segunda Guerra Mundial (1939-1945), muitas maisons, como a Chanel, Vionnet, entre outras, fecharam as portas. É somente na segunda metade do século XX que a atenção à moda é retomada novamente. Um fato importante no pósguerra foi o New Look, de Christian Dior, que surge para trazer de volta a feminilidade da mulher por meio da cintura ajustada, busto realçado e saias rodadas, causando muitas críticas por parte dos mais conservadores. Nesse momento, Paris se ergue novamente retomando seu posto de centro cultural da Alta-Costura, inaugurando a Union Française des Arts du Costume (1948), antigo Musée des Arts Décoratifs (FERREIRA, 2015).

Em meados de 1980, o museu passa a se chamar Musée de la Moda et du Textile. Atualmente o espaço conta um acervo de 19.000 peças de vestuário, além de acessórios e outras peças, em um total de 86.000 obras, que contam a História da moda e da indústria têxtil. Grande parte do acervo é fruto de doações particulares, de indústrias do setor têxtil e de estilistas como: Chanel, Mc Queen, Yves Saint Laurent, dentre outros. Ainda sobre o século XX, a pesquisadora Christine Azzi (2010) esclarece que:

O final do século XX consolida o desenvolvimento de museus de moda. São, pelo menos, seis instituições consagradas ao tema: o Museu of Costume, o Fashion Institute of Tecnology, o Musée Galliera, o Museu Nacional do Traje e da Moda, o Kyoto Costume Institute e o Atelier Musée du Chapeau (AZZI, 2010, p. 48).

Em meados de 1963, é inaugurado o Museum Costume, em Bath, que em 2007 é rebatizado de Fashion Museum, criado a partir da coleção da estilista Doris 
Langley Moore. Nesse mesmo período, os Estados Unidos passam a marcar presença com mais força no quesito museológico. Contudo, o maior desenvolvimento no ramo se dá após a criação do Fashion Institute of Tecnology Museum, fruto de um desmembramento do Costume Institute do Metropolitan Museum. O Costume Institute representava um departamento dentro de um museu maior que se dedicava às artes em geral. O FIT Museum faz parte do Fashion Institute of Tecnology, criado em 1944 como um centro de pesquisa e ensino sobre moda. Consolida-se como um grande difusor na questão profissional, abordando o design, moda e a indústria têxtil. Sob a direção de Valerie Steele desde 2003, a coleção do FIT Museum conta com um acervo de mais de 50.000 peças, incluindo roupas e acessórios (AZZI, 2010).

A década de 70 trouxe consigo novas conquistas para os museus de moda, colocando em cena dois museus na Europa e um no Japão. Em 1977 surgem o Musée Galliera, em Paris, e o Museu Nacional do Traje e da Moda, em Lisboa. No Japão, o Kyoto Costume Institute nasce em 1978. O Musée Galliera conta com um acervo de 90.000 peças, que abrangem três séculos de moda, com exposições permanentes e temporárias. O Museu Nacional do Traje e da Moda foi criado após uma exposição realizada em 1947 sobre o traje civil português. O Kyoto Costume Institute foi criado pelo Ministério da Cultura do Japão e marca a entrada do país asiático no mundo da moda, sobretudo com destaque para a moda contemporânea. A instituição enfatiza o olhar japonês na moda, como, por exemplo, na exposição Japonism in Fashion realizada em 1994 (AZZI, 2010).

O século $X X I$ se inicia com o surgimento de novos museus dedicados à moda, com destaque para: Mode Museum, na Bélgica (2002); Museo de la Moda, em Santiago do Chile (2006); e o Fashion and Textile Museum, em Londres (2007). O Mode Museum mais conhecido como MoMu, tem mais de 25.000 objetos, com o foco em vestuário, têxteis e acessórios. As peças mais antigas datam do século XVII. A criação do Museo de la Moda se deu após criação da Fundação Fashion Museum, iniciada em 1999 por Jorge Yarur Bascuñán, empresário da indústria têxtil. O museu foi fundado pela família Yarur Bascuñán, com acervo composto a partir de doações e aquisições nacionais e internacionais de vestuário, têxteis, artes decorativas e sportswear, que datam desde o século XVII até os dias atuais. O Museo de la Moda abriu as portas em 2007, após anos de pesquisa e preparo, com foco em um longo trabalho de construção de espaços específicos para armazenamento, além de cuidados com a coleção seguindo as normas internacionais de conservação, restauro 
e adaptação de um museu com essas especificidades, estabelecendo-se como um marco na museologia da moda na América Latina. O Museu da Moda e Têxtil figura como um centro de vanguarda para a moda contemporânea, têxteis e joias em Londres. Fundado pela designer britânica Zandra Rhodes, o centro apresenta um programa de exposições temporárias que exploram elementos de moda, têxteis e joias, bem como cursos para alunos e empresas criativas. O museu tem como proposta não apenas exibir e coletar itens relacionados com os elementos das exposições, mas oferecer referências para uma nova geração de designers e criativos em geral, tornando-se um centro de aprendizagem e trabalho em rede para a indústria do design (AZZI, 2010)

Fato é que a moda nunca esteve tão em evidência quanto nas últimas décadas. Prova disso são as constantes exposições realizadas em museus específicos e de arte. Essas exposições põem em prática uma grande problemática: ver a moda/roupa como cultura material, percebendo a moda não apenas pelo prisma do consumo, mas também como guardiã de uma grande história, a do vestuário.

Dentro desse contexto, é possível perceber que tem havido, desde o século $\mathrm{XIX}$, um número crescente de museus voltados à questão da moda, em que se percebe também, cada vez mais, a presença da curadoria de moda nos museus, tanto nos específicos quanto nos de arte.

\section{A MODA COMO DISPOSITIVO DE MEMÓRIA}

A moda não pertence a todas as épocas, mas retrata o que acontece em determinados momentos da vida da sociedade, se estabelecendo como um dispositivo cultural (LIPOVETSKY, 2009). "O termo moda, do latim 'modus', em seu significado mais amplo, significa escolha, ou melhor, mecanismos de escolhas realizadas tendo como base critérios de gosto" (CONTI, 2008, p. 223). Vendo a moda na sociedade e de como ela foi aos poucos se estruturando, Gilles Lipovetsky (2009) diz que:

A moda não é mais um enfeite estético, um acessório decorativo da vida coletiva; é sua pedra angular. A moda terminou estruturalmente seu curso histórico, chegou ao topo do seu poder, conseguiu remodelar a sociedade inteira à sua imagem: era periférica, agora é hegemônica (LIPOVETSKY, 2009, p.13)

A moda pode ser entendida também como um processo para distinção social dos indivíduos, estabelecendo-se inúmeras vezes como uma moda de classes. 
Ela revela o espírito de um tempo e se reinventa continuamente, buscando referências no passado. Não raro percebemos alguns designers contemporâneos buscando imagens do passado, transformando-as e readaptando-as ao gosto moderno. "A moda, num certo sentido é mudança, e nas sociedades ocidentais modernas não existe roupa fora de moda: a moda estabelece os termos de todos os comportamentos em relação ao modo de vestir" (WILSON, 1989, p.14).

Um exemplo interessante na moda nos últimos anos é o resgate das ombreiras dos anos 80 , que foram trazidas novamente ao cenário da moda nos anos 2000, dessa vez com algumas adaptações. Um processo, enfim, que se modifica e se reinventa, criando novas significações e apropriações de contextos já existentes, como um sistema em constante movimento. Segundo Crane (2008, p. 159), "as modas são um aglomerado de normas e códigos que constituem estilos reconhecidos em períodos específicos [...] que são continuamente revisados e modificados".

Para além do caráter frívolo, a moda pode ser entendida como um sistema, em que o signo é elaborado de tempos em tempos, não especificamente pela massa, mas por grupos específicos que a reinterpretam de acordo com a necessidade da massa. "Hoje em dia, os modelos apresentados pela cultura popular são amplamente copiados e não se podem presumir que todos copiem os estilos da última moda" (CRANE, 2008, p. 159).

A moda, através das roupas e acessórios em geral, pode ser considerada um elemento integrante e expressivo de qualquer cultura. Por outro lado, cabe salientar que existe na moda, atualmente, uma necessidade de resgate de valores culturais, políticos e sociais. Sobre essa relação com as questões culturais e políticas, e vendo a moda pelo viés político-cultural, podemos nos deter na obra de designers que a usam para discutir tais questões, como é o caso do designer de moda brasileiro Ronaldo Fraga.

Ronaldo Fraga apresenta um trabalho voltado às questões culturais e políticas e, em especial, duas coleções suas nos chamam atenção; a primeira é a Coleção Rio São Francisco, na qual o designer explora questões relativas à transposição do rio e sua importância para o homem nordestino.

As 'águas' do São Francisco não cabem em uma só coleção de moda, em um só livro e muito menos em uma única exposição, portanto essa não é uma mostra de acervo. São instalações costuradas entre a moda e cultura ribeirinha (FRAGA, 2011, p.1). 
A segunda é Quem matou Zuzu Angel? que traz à tona a ditadura militar no Brasil e faz menção à designer de moda Zuzu Angel, que teria sido vítima da ditadura após questionamentos sobre a morte de seu filho Stuart Angel. A coleção se firma nesse sentido como uma porta-voz de um tempo vivido no país.

Ainda pensando a moda como um dispositivo cultural importante, podemos citar a obra do designer de moda Husssein Chalayan, que pontua em algumas de suas coleções questões sociopolíticas vividas por ele em sua terra natal e que se desdobram em questionamentos, sobretudo do âmbito cultural, personificado em sua obra, tanto nos desfiles como nas peças em si.

\subsection{A ROUPA COMO UM DISPOSITIVO DE MEMÓRIA}

As roupas participam de muitos acontecimentos de nossa vida e servem como menção para a demarcação da memória. Por exemplo, uma determinada peça de roupa da moda, ou objeto, pode nos remeter a uma determinada época na qual aquele objeto ficou em evidência, seja pela forma ou pelo desejo de tê-lo.

\section{Objetos da memória}

As roupas se tornam objetos-documento porque retratam uma experiência, sendo importantes resquícios de memória. A partir desse prisma, podemos entender a roupa como um dispositivo de memória da sociedade.

A roupa não é apenas um objeto de um fenômeno efêmero que é a moda, mas ela resiste aos corpos, os corpos vêm e vão e elas sobrevivem. A roupa veste o seu próprio 'eu', usando o corpo em sua forma mais pura e por uma espécie de tautologia remete ao próprio vestuário (BARTHES, 1979, p. 245).

Ela constrói situações que excedem o campo físico e alcançam o inconsciente. "A roupa - como objeto material de uso cotidiano - é dotada de elementos subjetivos, composta por uma memória sensitiva e carregando nossa forma física, nosso cheiro, nosso suor. Carrega também memórias, nomes e o espírito de quem a utilizou" (FAGUNDES, 2011, p. 1). "A memória é constituída por pessoas, personagens" (POLLACK, 1992, p. 2). A roupa assumiria para o homem esse papel de personagem diante da relação estabelecida entre homem e objeto. 
Sobre a ligação entre a memória e os objetos que carregam lembranças ligadas ao universo sensorial e despertam nossa sensibilidade, Patrícia Sant'Anna (2010) esclarece:

\begin{abstract}
Vestuários são objetos que recaem diretamente no universo sensorial: visão, tato, olfato e mesmo audição (quem não passou por um trecho de literatura que descrevia o farfalhar de um tecido?). Neste sentido as peças estabelecem-se como elementos de conservação silenciosa, pois despertam a sensibilidade, levando a uma significação a partir do estímulo. Este traço semântico que a roupa pode portar é apropriado de diversas maneiras pelos museus (SANT'ANNA, 2010, p. 220).
\end{abstract}

O vestuário-moda é, de fato, como um artefato privilegiado que nos permite pensar sobre a maneira como ele se torna um objeto-documento. "De modo geral, quando uma peça adentra o museu ela é sempre tratada como documento, é isso que dá início a aventura do processo de musealização de uma peça de moda (roupa, acessório, calçado)" (SANT'ANNA, 2010, p. 222). Ainda sobre os objetos no espaço museológico, o pesquisador Douglas Crimp (2015) nos diz que: "Em uma coleção é crucial que o objeto esteja livre de todas as suas funções originais para que possa se relacionar da maneira mais próxima possível com seus equivalentes." (CRIMP, 2015, p. 179). Nesse sentido, entende-se que este mesmo objeto junto com muitos outros ajudará a contar uma história maior, de diálogos e reflexões.

\title{
4 ESTUDO DE CASO: HUSSEIN CHALAYAN E A SUA ENTRADA NO ESPAÇO MUSEOLÓGICO
}

Roupas que interagem com as mudanças climáticas, outras que se apropriam dos aspectos do design de móveis emprestados e ainda aquelas em que se busca as referências aerodinâmicas, usadas com o mesmo material de carcaças de aviões. Hussein Chalayan pode não ter um nome tão conhecido do grande público contemporâneo, mas chama atenção silenciosamente pela genialidade. O designer vem surpreendendo desde 1993, ano em que se formou em Design. Apresentou peças corroídas e apodrecidas pelo tempo, já ganhou exposições em Paris, Londres e Veneza. Em quase duas décadas de criações surpreendentes, Chalayan tem chamado atenção por produzir um design de moda diferenciado, que aponta para questões culturais importantes (CLARK, 2011).

Guerra, exílio, alienação, poder, nomadismo, deslocamentos e memória são temas recorrentes na produção do designer Hussein, aliados a um design com relações de proximidade com a arte. 
Chalayan distinguiu-se de outros designers através de sua abordagem multidisciplinar, se utilizando de várias mídias e linguagens como escultura, design de móveis, vídeo e efeitos especiais. Ele estava sempre em contato com o espírito da época, inspirando-se diretamente nas realidades políticas, econômicas e sociais (CLARK, 2011).

Desde 2002, Chalayan vem transitando em outros espaços para além da passarela, possibilitando que o público tenha acesso a suas produções em museus, centros culturais e galerias de arte. Em 2011, a curadora de moda Pamela Golbin apresentou no Musée Les Arts Décoratifs, em Paris, a exposição Fashion Narratives. Esta curadoria pode ser entendida como uma espécie de retrospectiva sobre a obra de Hussein Chalayn, incorporando uma série de coleções. Com sua abordagem única no design, ele fica na fronteira entre moda, arquitetura e design. Seu trabalho é caracterizado por um rigor intelectual e uma busca pela perfeição técnica que muitas vezes desafia estereótipos da moda. Suas coleções ao longo dos anos foram, na verdade, expressões de seu desenvolvimento intelectual. Elas revelam suas origens multiculturais, o questionamento do mundo, enquanto suas influências remetem à sua história pessoal - suas viagens e revoltas e problemas, guerras e conflitos da sociedade. Seu processo criativo explora diversas áreas como antropologia, filosofia, arquitetura e ciência, entrelaçando-os, por vezes de forma autobiográfica, que serve como um tema unificador para suas coleções (FOGG, 2013).

A exposição comporta toda produção do designer, de 1993 aos dias atuais. Além de peças de suas coleções, há também suas instalações multimídia e filmes encomendados pelas galerias de arte, bem como desfiles de moda, vídeos, desenhos, projeções e outros materiais de pesquisa mostrados lado a lado para ilustrar processos do designer.

A exposição apresenta formato não cronológico, e foi pensada de acordo com os temas que Hussein Chalayan trabalhou em suas coleções. A primeira parte trabalha a questão da exploração das fronteiras políticas, culturais, religiosas, geográficas e técnicas. Nesta seção estão os vestidos de sua primeira coleção que foram enterrados, além dos vestidos postais frutos de sua primeira coleção comercial, Cartesia (outono / inverno 1994). Remanescente de aerogramas, estes vestidos têm as mesmas dobras das cartas que ele enviou quando era criança. Os vestidos de correio aéreo foram inseridos dentro de um envelope, pronto para postar. 
As transformações e as metamorfoses do corpo sempre foram temas recorrentes para Chalayan e ele usa a mais recente tecnologia para ilustrá-la em apresentações espetaculares. Em Afterwords (outono/inverno 2000), que foi inspirada na guerra do Kosovo e a limpeza étnica em Chipre, que levou a um êxodo em massa de pessoas de suas casas, o designer cria uma sala com peças de mobiliário que desaparecem totalmente quando as modelos começam a interagir com o espaçocircundante. As modelos entram, tiram o estofado das poltronas e começam a usá-los como vestidos, dobram as cadeiras que se transformam em malas, além da mesa de centro que se transforma em uma saia-mesa. Assim, evacuam a cena em momento épico no cenário dos desfiles de moda contemporânea.

No final da exposição, estão os trabalhos mais recentes de Chalayan, inspirados pelo Japão, um país conhecido por seu rigor intelectual, rigor presente no projeto Sakoku (primavera / verão 2011) ou "país bloqueado", referindo-se à política de isolamento do Japão, que até meados do século XIX proibia quase todos os estrangeiros de entrar no país e qualquer cidadão japonês de sair, sob pena de morte. Explorando artifícios como sombra, água, arquitetura, tecnologia, teatro, traje, poesia e isolamento, que afetam a cultura japonesa, o designer apresentou um tipo de vestido escultura robótico, que se movimenta em direção à modelo.

Chalayan continuou com a temática e seguiu com Kaikoku ou "campo aberto", termo para designar o período em que o Japão se abriu para a cultura ocidental durante o rescaldo da II Guerra Mundial. Centrando-se no híbrido resultante de culturas, a coleção tinha tons de austeridade com casacos sob medida e ajustáveis. Ao final da coleção, Chalayan traz um vestido que se movimenta e que é uma peça de resistência: um vestido flutuante em ouro, feito de uma resina de poliéster e fibra de vidro cápsula, controlado por controle automatizado. Em sua superfície laqueada, estão preciosos cristais descansando e esperando o momento certo de flutuar no ar, criando uma magia para todos ao seu redor, simbolizando a polinização de ideias (CLARK, 2011).

Por tudo isto, e tendo em vista a produção do designer Hussein Chalayan, consideramos que o diálogo entre moda e a memória se faz necessário para que o enquadramento do design não represente somente valores dominantes e consagrados, na intenção de promover mais narrativas do design com práticas que se relacionem com a memória, de modo que as relações entre tempo e espaço ganhem outras formas de abordagem. 


\section{CONSIDERAÇÕES FINAIS}

O objetivo desta pesquisa foi identificar as relações entre moda, memória e museu, observando a produção e a obra do designer Hussein Chalayan. Examinamos questões ligadas à moda como um dispositivo de memória que foi percebida não somente na questão do design da roupa em si, mas na questão da elaboração de peças de roupa com uma carga memorialística, Consideramos as roupas como um objeto que tem uma forte ligação com a memória, e esse processo pode se dar tanto na elaboração, como é o caso da produção de Hussein Chalayan, como posteriormente, ao adentrar um espaço museológico, em que tempo acaba legitimando algumas peças e seus designer.

Procuramos percorrer alguns caminhos entre a moda e o museu, buscando estabelecer diálogos entre ambas as áreas. Nesse sentido, apontamos possibilidades para uma conversa entre o surgimento de exposições e museus de moda e de como esse fenômeno tem ganhado força nos últimos tempos. Lembramos que a moda, enquanto um campo, concentra relações de dominação econômica e simbólica que pronunciam táticas para custeio de seu funcionamento. Dessa forma, a moda oferece particularidades como campo da cultura, e a memória passa a construir um valor duradouro que proporciona estratégias de manutenção desse campo. A relação entre moda e memória promove a construção de lugares que entrecruzam diferentes narrativas, vozes e lembranças, sob o contexto da moda e da produção do design. Com isto, pretendemos dar prosseguimento futuro a esta pesquisa, com o anseio de que novas possibilidades surjam com relação ao tema, e que a moda possa ser percebida como um dispositivo de cultura e memória ${ }^{3}$.

\section{REFERÊNCIAS}

ANDRADE, Rita. Boué Soeurs RG 7091: a biografia cultural de um vestido. Tese (Doutorado) - Programa de História, Pontifícia Universidade Católica de São Paulo, 2008.

\footnotetext{
3 Texto revisado por Alessandra Pinto Ribeiro Medina, bacharela em Comunicação Social pela Universidade Federal do Maranhão e mestranda em Comunicação pelo Programa de Pós-Graduação em Comunicação - Mestrado Profissional da UFMA. E-mail: aleeh.medina@gmail.com.
} 
AZZI, C. F. Vitrines e coleções: quando a moda encontra o museu. Rio de Janeiro: Memória Visual, 2010.

BARTHES, Roland, Sistema da moda. Editora Martins Fontes, São Paulo, 2009. BASTIAN, Winnie. Subvertendo a tradição: Moda e Arte na produção de Alexander McQueen. 2011.

BAUDELAIRE, Charles. Sobre a modernidade o pintor da vida moderna / Charles Baudelaire; [organizador Teixeira Coelho].— Rio de Janeiro: Paz e Terra, 1996.

BAUDRILLAND, Jean. O sistema dos objetos. São Paulo: Perspectiva, 2006.

BENARUSH, Michelle Kauffmann. A memória das roupas. In:. Revista Dobras, n.12, Estação das Letras e Cores, 2012.

BENARUSH, Michelle Kauffmann. Moda é Patrimônio. Anais do VIII Colóquio de Moda $5^{\circ}$ Congresso Internacional, 2010.

BONSIEPE, Gui. Design, Cultura e Sociedade. São Paulo: Blucher, 2011.

BRAGA, João. História da Moda: uma narrativa. $7^{a}$. ed. São Paulo: Editora Anhembi Morumbi, 2007.

BUENO, Rodrigo Poreli Moura. História e Memória: perspectivas Sócio-Culturais. 2011. CERVA, Ana Carine. Construção, reconstrução e disputa pela memória coletiva e identidade étnica nos campos de cima da serra do Rio Grande do Sul: distrito caxiense de Vila Seca. 2014.

CHARTIER, Roger. A História da Cultura: entre práticas e representações. Algés, Portugal: Difusão Editorial AS, 2002.

CONTI, Giovanni Maria. Moda e cultura de projeto industrial: hibridação entre saberes complexos. in: Design de moda olhares diversos. Barueri: Estação das Letras, 2008. CLARK, Judith; DE LA HAYE, Amy; HORSLEY, Jeffrey. Exhibiting Fashion: Before and After 1971. 2014.

CLARK, Judith et al. Hussein Chalayan. Rizzoli International Publications, 2011.

CRANE, Diana. A moda e seu papel social: classe, gênero e identidade das roupas. São Paulo: SENAC, 2008.

CRIMP, Douglas. Sobre as ruínas do museu; tradução: Fernando Santos; revisão da tradução Aníbal Mari. - São Paulo: Martins fontes, 2005.

DALLARI, Heloisa. Design e Exposição: das vitrines para as novas telas. Tese de Doutorado. São Paulo, Brasil: Faculdade de Arquitetura e Urbanismo da Universidade de São Paulo, 2008.

DENIS, Rafael Cardoso. Uma introdução à história do design. São Paulo: Edgard Blücher, 1998.

FAGUNDES, Joyce Corrêa. O RG Feminino Impresso no Vestuário. Trabalho apresentado ao XI Congresso Luso afro Brasileiro de Ciências Sociais, Diversidade e Desigualdade, Salvador, 2011.

FERREIRA, Diêgo Jorge Lobato. A moda pelo viés da memória: das passarelas para o museu. Anais do Moda Documenta: Museu, Memória e Design - Maio, 2015.

FORTY, Adrian. Objetos de desejo: design e sociedade desde 1750. São Paulo: Cosac Naify, 2007.

FRAGA, Ronaldo. Entrevista sobre a exposição Rio São Francisco. 2011. Disponível em: $<$ http://saofranciscoronaldofraga.com.br/>. Acesso em: 20 jul. 2015.

GUEDES, Renato Celestino; TEIXEIRA, Edilene Lagedo. A moda feminina na década de 70: o exemplo Zuzu Angel. In: Anais do Colóquio Internacional Gênero, Feminismos e Ditaduras no Cone Sul. Universidade Federal de Santa Catarina, 2008.

HALBWACHS, Maurice. A memória coletiva. São Paulo: Centauro, 2004.

IBRAM, INSTITUTO BRASILEIRO DE MUSEUS -. Lei n 11.904, de 14 de janeiro de 2009. Brasília, Brasil: Presidência da República, Casa Civil, Subchefia para Assuntos Jurídicos, 2009.

LE GOFF, Jaques. História e Memória. Campinas: Unicamp, 2013.

LIPOVETSKY, Gilles. $O$ império do efêmero: a moda e seu destino nas sociedades modernas. Editora Companhia das Letras, 2009. 
MORAES, Nilson. Políticas Públicas, Políticas Culturais e Museus no Brasil. Rio de Janeiro: MAST/UNIRIO, Vol.2, No 1. 2009. p. 54-69. Disponível em:

<http://revistamuseologiaepatrimonio.mast.br/index.php/ppgpmus/article/view/46/26>. Acesso em: 08 ago. 2009.

NORA, Pierre. Entre memória e história: a problemática dos lugares. Projeto História:

Revista do Programa de Estudos Pós-Graduados em História e do Departamento de História da PUC-SP, São Paulo: PUC, n. 10, 1993. p. 7-28.

NORMAN, Donald A. Design emocional: por que adoramos ou detestamos os objetos do dia-a-dia. Rio de Janeiro: Rocco, 2008.

NOROGRANDO, Rafaela. Como é formado o patrimônio cultural: Estudo museológico em Portugal na temática Traje/Moda. Dissertação (Mestrado) - Depto. De

Antropologia/FCTUC - Universidade de Coimbra, Portugal, 2011.

NOROGRANDO, Rafaela. Exposições Museológica: A Moda por narrativas, experiências e conexões. Tese (doutorado). Universidade de Aveiro, 2015.

PINHEIRO, Marcos José. Museus, memória e esquecimento: um projeto da modernidade. Editora E-papers, 2004.

POLLAK, Michael. Memória e identidade social. Estudos Históricos, Rio de Janeiro, v. 5, n. 10, 1992.

ROCHE, Daniel; KFOURI, Assef. A cultura das aparências: uma história da indumentária, séculos XVII-XVIII. Senac, 2007.

SANT'ANNA, Patrícia. Coleção Rhodia do MASP - Um estudo sobre o design de vestuário no Brasil (1959-1972), Tese (Doutorado) em História da Arte-Universidade Estadual de Campinas, 2010.

SILVA, Helenice Rodrigues da. "Rememoração"/ Comemoração: as utilizações sociais da memória. Revista Brasileira de História. 2002.

SORCINELLI, Paolo. Estudar a moda: corpos, vestuário, estratégias. São Paulo: SENAC. 2008.

STALLYBRASS, Peter. O casaco de Marx: roupas, memória, dor. São Paulo: Autêntica, 2012

WILSON, Elizabeth; FREIRE, Maria João. Enfeitada de sonhos: moda e modernidade. 1989. 